\title{
Smad2 and Smad3 as mediators of the response of adventitial fibroblasts induced by transforming growth factor $\beta 1$
}

\author{
MIN REN $^{1 *}$, BO WANG ${ }^{1 *}$, JIDONG ZHANG $^{1}$, PING LIU $^{3}$, YIJING LV $^{1}$, \\ GUILIN LIU ${ }^{4}$, HONG JIANG ${ }^{2}$ and FENYE LIU ${ }^{5}$ \\ ${ }^{1}$ Department of Traditional Chinese Medicine; ${ }^{2}$ Laboratory of Cardiovascular Remodeling and Function Research, \\ Qilu Hospital of Shandong University, Jinan, Shandong 250012; ${ }^{3}$ Department of Health Management, \\ The Second Hospital of Shandong University, Jinan, Shandong 250033; ${ }^{4}$ Medical Department, \\ Hospital Affiliated to Shandong Academy of Medical Science, Jinan, Shandong 250062; \\ ${ }^{5}$ Department of Traditional Chinese Medicine, Shandong Provincial Hospital, Jinan, Shandong 250021, P.R. China
}

Received November 3, 2010; Accepted March 3, 2011

DOI: $10.3892 / \mathrm{mmr} .2011 .458$

\begin{abstract}
Transforming growth factor $\beta 1$ (TGF- $\beta 1$ ) is a known pleiotropic growth factor in cell proliferation, migration and phenotypic transition. Fibroblasts are considered the most reactive in the vascular wall. We aimed to explore the effect and mechanism of TGF- $\beta 1$ on aortal adventitial fibroblasts (AFs) induced by TGF- $\beta 1$. AFs were cultured in vitro by tissue explants. After stimulation by TGF- $\beta 1$ and treatment with small interfering RNA (siRNA)-Smad2 and siRNA-Smad3, MTT and the transwell chamber techniques were used for assessing AF proliferation and migration. The expression of phospho (pho)-Smad2, pho-Smad3, Smad7, $\alpha$-smooth muscle actin (SMA) and collagen I and III were evaluated by Western blot analysis and real-time RT-PCR. After stimulation by TGF- $\beta 1$ for $24 \mathrm{~h}$, the proliferation and migration of treated AFs were higher compared to those of untreated AFs, as was the expression of Smad2, Smad3, phoSmad2, pho-Smad3, SMA and collagen I and III $(\mathrm{P}<0.05)$, but not Smad7 ( $>>0.05)$. Knockdown of Smad2 and Smad3 inhibited proliferation and migration of $\mathrm{AFs}$ and downregulated the expression of SMA and collagen I and III $(\mathrm{P}<0.05)$. TGF- $\beta 1$ plays a key role in remodeling processes by contributing to the proliferation, migration and phenotypic modulation of AFs and collagen composition. The mechanism may be related to both the Smad2 and Smad3 signaling pathways.
\end{abstract}

Correspondence to: Dr Jidong Zhang, Department of Traditional Chinese Medicine, Qilu Hospital of Shandong University, 107 Wenhua Xi Road, Jinan, Shandong 250012, P.R. China E-mail: drzhangjidong@163.com

Key words: adventitial fibroblasts, transforming growth factor $\beta 1$, Smad2, Smad3

\section{Introduction}

Adventitia, traditionally considered supporting tissue that provides nourishment and support to the blood vessels, is emerging as a prominent factor in the pathogenesis of cardiovascular diseases. Adventitia plays an important role in controlling vascular remodeling and vessel tone through regulatory systems. It is the most sensitive layer responding to blood pressure (1). One of the earliest signs found in hypertensive remodeling is the change in adventitial cells. Adventitial fibroblasts (AFs), the main adventitial cell type, drive remodeling and may initiate other changes, such as alterations in the arrangement of neointimal proliferation, smooth muscle cells and extracellular matrix (ECM), which are expected to lead to vascular remodeling (2-4). Therefore, determining the mechanism responsible for adventitial activation provides a potential therapeutic strategy for vascular diseases.

Transforming growth factor $\beta 1$ (TGF- $\beta 1$ ), up-regulated at the site of vascular injury, is a multifunctional cytokine involved in various functions, such as promoting proliferation, adhesion, migration, synthesis of ECM and myofibroblast formation in fibrosis, among many cell types $(5,6)$. TGF- $\beta 1$ is an important perivascular growth factor in the adventitia (7), and adventitial cells play a significant role in vascular remodelling processes under the influence of TGF- $\beta 1$ (8). The classical signal transduction pathway of the TGF- $\beta$ family is through Smad (9). The decrease of the transcription of TGF- $\beta 1$ response genes is a consequence of inhibiting Smad3 phosphorylation in human dermal fibroblasts (10). Treating cells with SIS3, a potent and selective inhibitor of Smad3, may reduce TGF- $\beta 1$-mediated up-regulation of $\alpha 2$ (I) collagen mRNA (11). Smad2, 3 and 4 participate in AF proliferation stimulated by TGF- $\beta 1$ (12). However, whether the TGF- $\beta 1 /$ Smad signaling pathway takes part in stimulating AFs and remains unclear, as does its precise effect.

In the present study, we hypothesized that the Smad2 and 3 signaling pathways are simultaneously involved in the proliferation, migration, transdifferentiation and ECM deposition of AFs stimulated by TGF- $\beta 1$. AF induction by TGF- $\beta 1$ 
Table I. Primers for quantitative real-time RT-PCR.

\begin{tabular}{llcc}
\hline Genes & \multicolumn{1}{c}{ Forward and reverse primers $\left(5^{\prime}-3^{\prime}\right)$} & Amplicon size $(\mathrm{bp})$ & Temperature $\left({ }^{\circ} \mathrm{C}\right)$ \\
\hline$\beta$-actin & F: GACAGGATGCAGAAGGAGATTACT & 142 & 57.9 \\
$($ NM-031144) & R: TGATCCACATCTGCTGGAAGGT & & 57.7 \\
Smad2 & F: GCCGAGTGCCTAAGTGAT & 153 & 57.3 \\
$($ NM-019191) & R: AGACTGAGCCAGAAGAGC & & 57.3 \\
Smad3 & F: TGTCATCTACTGCCGCTTGTG & 163 & 57.6 \\
$($ NM-013095) & R: CAACACTGGAGGTAGCACTGG & 289 & 59.5 \\
SMA & F: CTGGTATTGTGCTGGACTC & & 55.2 \\
$($ NM-031004) & R: CATCAGGCAGTTCGTAGC & 714 & 54.9 \\
Collagen I & F: GGCATAAAGGGTCATCGTG & & 55.2 \\
(NM-053304) & R: GAACCTTCGCTTCCATACTC & 190 & 55.4 \\
Collagen III & F: CCCAGAACATTACATACCACT & & 53.7 \\
$($ NM-032085) & R: GTCTTGCTCCATTCACCAG & 55.2 \\
\hline
\end{tabular}

and then interference by small interfering RNAs (siRNAs) was used to examine the effect of TGF- $\beta 1$ through Smad2 and 3 in the remodeling processes.

\section{Materials and methods}

Cell culture. AFs were obtained from the thoracic aorta adventitia of Wistar-Kyoto rats. Adventitia was carefully decorticated, cut into small pieces $\left(1 \mathrm{~mm}^{3}\right)$ and distributed equally into culture flasks, then cultured in DMEM supplemented with heat-inactivated fetal calf serum (FCS) $(10 \%, \mathrm{v} / \mathrm{v})$ and $10 \mathrm{mmol} / \mathrm{l}$ HEPES in a humidified atmosphere with $5 \%(\mathrm{v} / \mathrm{v}) \mathrm{CO}_{2}$ at $37^{\circ} \mathrm{C}$. Three to seven days later, $\mathrm{AFs}$ were observed to grow out from the tissues, and cells at passages 3-8 were used in assays. Immunocytochemistry with vimentin (Wuhan Boster Biological Technology, LDT, China) and $\alpha$-smooth muscle actin (SMA; Abcam, Cambridge, UK) was used to identify AFs and their purity.

Experimental groups. AFs were divided into two groups: AFs treated with TGF- $\beta 1$ (20 ng/ml; recombinant human TGF- $\beta 1)$ (PeproTech, Rocky Hill, NJ, USA) and control (untreated) AFs. Other AFs were divided into five groups: TGF- $\beta 1$-treated AFs, negative (non-targeting siRNA duplexes) + TGF- $\beta 1$-treated AFs, siRNA-Smad2/3 + TGF- $\beta 1$-treated AFs and control (untreated) AFs.

SiRNA method. Target siRNAs were identified by a siRNA design tool (Dharmacon Inc., Lafayette, CO, USA) and the transfection was performed according to the manufacturer's instructions. The duplexes of siRNAs targeting Smad2 (GenBank no. NM-019191) were 5'-GCC AGUUACUUAUUCAGAATT-3' and 5'-UUCUGAAUAAGU AACUGGCTG-3' and those targeting Smad3 (GenBank no. NM-013095) were 5'-GCUGUUCCAGCGUGUCUUATT-3' and 5'-UAAGACACGCUGGAACAGCGG-3'. All siRNAs were chemically synthesized by Shanghai GenePharma Co. AFs were seeded at a density of $50 \%$ the day before transfection, then treated with Lipofectamine 2000 (Invitrogen, Carlsbad, CA, USA) and $100 \mathrm{pmol} / \mathrm{ml}$ of siRNA mixed in
Opti-MEM. Twenty-four hours after transfection, the cells were stimulated by TGF- $\beta 1$ and incubated for another $24 \mathrm{~h}$. Western blot analysis was used to confirm the effect of knockdown.

MTT assay. AFs were seeded in 96-well plates at $2.0 \times 10^{4}$ cells/ well. After incubation in complete medium containing $10 \%$ FCS overnight, the cells were serum-starved and synchronized for $4 \mathrm{~h}$. AFs in the TGF- $\beta 1$ experiment were treated with TGF- $\beta 1$ for $24 \mathrm{~h}$. An amount of $20 \mu \mathrm{l}$ MTT $(5 \mathrm{mg} / \mathrm{ml})$ was added, followed by incubation for $4 \mathrm{~h}$ at $37^{\circ} \mathrm{C}$. Finally, the medium was removed and the cells were lysed with DMSO $(150 \mu \mathrm{l})$ for $15 \mathrm{~min}$. The absorbance of the samples was recorded at $490 \mathrm{~nm}$ using a microplate reader. Six wells per treatment were used. Wells with only MTT and DMSO served as blank controls.

Transwell migration assay. AFs were grouped and treated as described above. Cells were cultured in serum-free DMEM for $4 \mathrm{~h}$ prior to the migration assays. The migration of the AFs was measured using a transwell chamber apparatus (Greiner Bio One Ltd., Germany) (8- $\mu \mathrm{m}$ pore size, $24.85-\mathrm{mm}$ diameter). Briefly, the cells were trypsinized and counted, a $600 \mu \mathrm{l}$ cell suspension at $5 \times 10^{5} / \mathrm{ml}$ in DMEM was added to the upper compartment of the chamber, and $1.5 \mathrm{ml}$ DMEM containing $10 \%$ FCS was added to the lower compartment. After incubation at $37^{\circ} \mathrm{C}$ for $6 \mathrm{~h}$, cells on the upper face of the membrane were removed with a cotton-tipped applicator. Then, the membranes were fixed in methanol and stained with H\&E. The number of migrated cells was counted in 5 random fields in each membrane. Each experiment was performed in triplicate.

Real-time RT-PCR. After treatment, total RNA was isolated from the AFs using TRIzol Reagent (Invitrogen) according to the manufacturer's instructions. RNA quality and concentration were determined with a spectrophotometer $\left(\mathrm{DU}^{\circledR} 800\right.$; Beckman, Palo Alto, CA, USA). RNA $(1 \mu \mathrm{g})$ was treated with DNase, then reverse transcribed by a standard protocol (Fermentas, Glen Burnie, MD, USA). Quantitative real-time 
RT-PCR was performed with a Light Cycler apparatus (Roche Diagnostics, Mannheim, Germany). Negative control samples (no template) were run concurrently and $\beta$-actin was used as an internal control. Primers are shown in Table I. Experiments were performed in triplicate. The relative mRNA expression of the genes was determined by the $2^{-\Delta \Delta \mathrm{Ct}}$ method.

Western blot analysis. Cells were treated as described and then harvested. Protein was extracted and detected, and $30 \mu \mathrm{g}$ protein samples were used for SDS-PAGE. After the protein was transferred onto nitrocellulose membranes, the membrane was blocked and incubated with antibodies: anti-Smad2 (1:1,000), anti-phospho (pho)-Smad2 (1:300), anti-Smad3 (1:300), anti-pho-Smad3 (1:500; all Cell Signaling Technology, Inc., Danvers, MA, USA), anti-Smad7 (1:500; R\&D Systems, Minneapolis, MN, USA), anti-SMA (1:200) and anti-proCOL1A1 (1:300, A-17; Santa Cruz Biotechnology, Santa Cruz, CA, USA). The bands were quantified by densitometry and normalized to the levels of $\beta$-actin.

Statistical analysis. Data are presented as the mean \pm SD and were analyzed using SPSS v16.0 (SPSS Inc., Chicago, IL, USA). One-way ANOVA was used to analyze intergroup differences. When only two groups were compared, the independent samples t-test was used. Data with abnormal distribution were analyzed by non-parametric statistics. $\mathrm{P}<0.05$ was considered statistically significant. All experiments were repeated at least three times.

\section{Results}

AF identification and Smad protein expression. Three to seven days after culture, AFs were observed to grow out from the tissues. Cells appeared in a single layer and were irregularly shaped with a large body. Immunocytochemistry demonstrated negative staining for SMA and positive staining for vimentin, which suggested the AFs had $100 \%$ purity. After treatment with $100 \mathrm{pmol} / \mathrm{ml}$ siRNA, Smad2 and 3 expression was knocked down to $<20 \%$ (Fig. 1A and B). Moreover, the knockdown was selective, because Smad3 protein levels were decreased by Smad3 siRNA only, as were Smad2 protein levels (Fig. 1C and D).

AF proliferation induced by TGF- $\beta 1$ inhibited by siRNA-Smad 2 and siRNA-Smad3. The MTT assay was used to quantify cell proliferation. TGF- $\beta 1$ treatment for $24 \mathrm{~h}$ resulted in a significant induction of cell proliferation as compared to the control group (Fig. 2). However, the proliferation decreased when Smad 2 or 3 expression was knocked down by siRNA $(\mathrm{P}<0.01)$, with no significant difference between $\mathrm{Smad} 2$ and 3 knockdown.

AF migration induced by TGF- $\beta 1$ inhibited by siRNA-Smad2 and siRNA-Smad3. After stimulation by TGF- $\beta 1$ for $24 \mathrm{~h}$, the migration of the AFs was significantly increased $(\mathrm{P}<0.01)$ (Fig. 3). However, the blockade of Smad2 and 3 expression by siRNA reduced the TGF- $\beta 1$-induced migration of the AFs $(\mathrm{P}<0.01)$. Smad3 was reported to play a crucial role in the proliferation and migration of fibroblasts induced by TGF- $\beta 1$ (13). Thus, the up-regulation of migration in response to TGF- $\beta 1$ in AFs may depend on both Smad2 and Smad3.
A
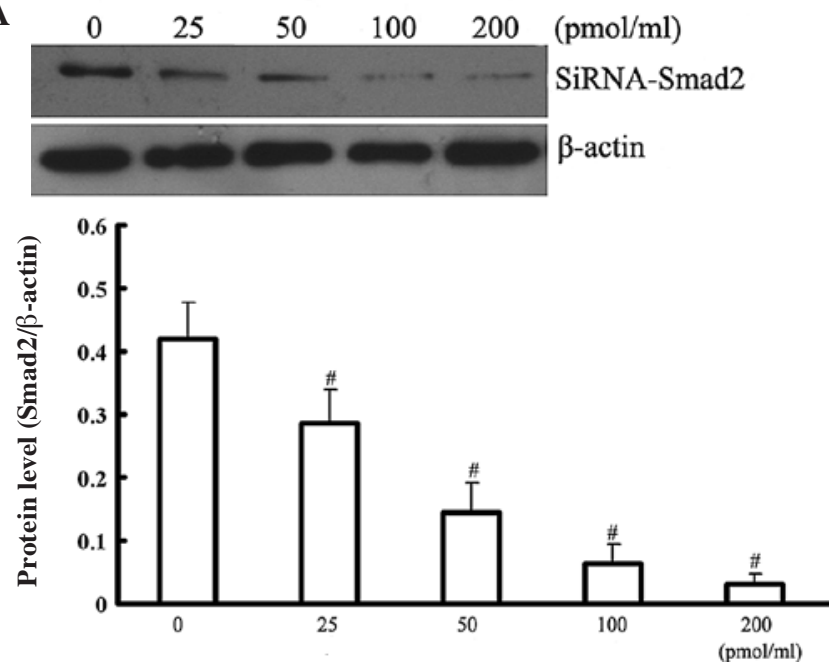

B
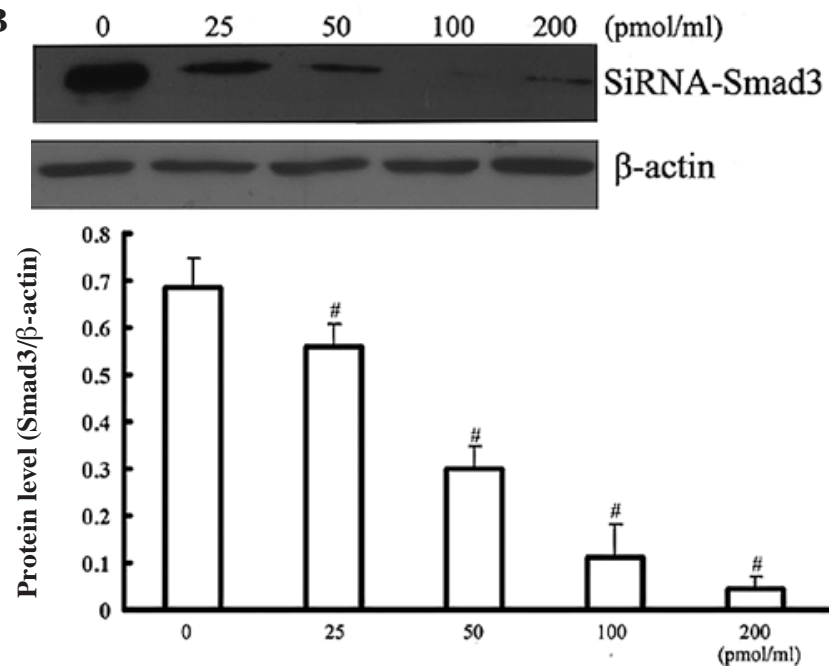

C

TGF- 31 SiRNA-Smad2 SiRNA-Smad3

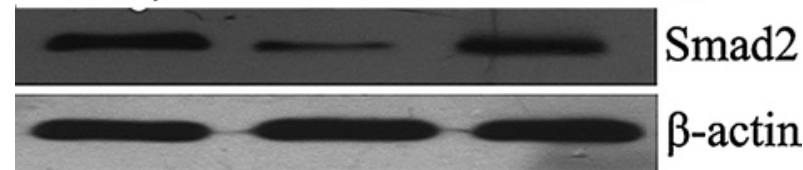

D

TGF- 31 SiRNA-Smad2 SiRNA-Smad3

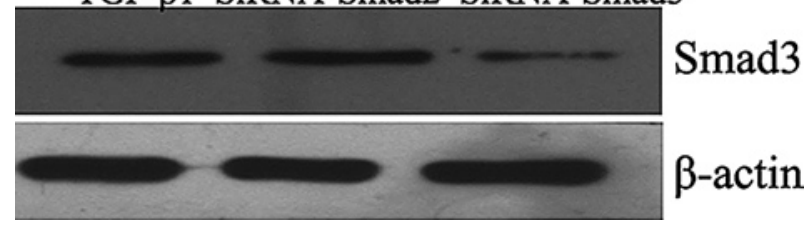

Figure 1. Efficiency of Smad knockdown. (A and B) Efficiency of Smad knockdown with different concentrations of siRNA oligomer. Knockdown of protein levels of (C) Smad2 and (D) Smad3 by Smad2 and Smad3 siRNA.

AF transdifferentiation and ECM deposition induced by $T G F-\beta 1$ requires Smad2 and Smad3. Under the influence of TGF- $\beta 1$, the expression of Smad2, SMA and collagen I and III was increased by 3.55-, 4.96-, 12.9- and 3.52-fold, respectively, compared to the control (Fig. 4A and B). The expression of Smad3 was also increased after stimulation (14). However, Smad7 expression did not change compared to the control $(\mathrm{P}>0.05)$, which agrees with findings that $\mathrm{Smad} 7$ is an immediate-early gene target of TGF- $\beta 1$ in fibroblasts $(15,16)$. 


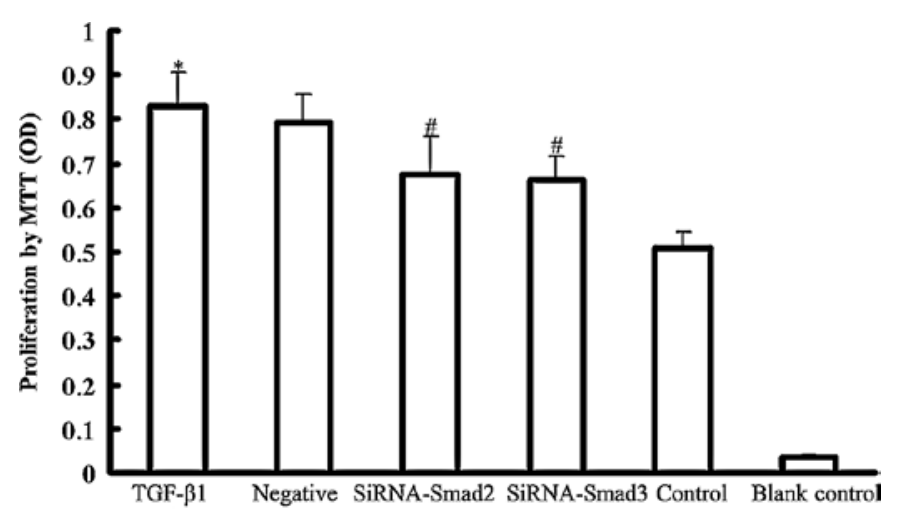

Figure 2. Effect of TGF- $\beta 1$ and siRNA on the proliferation of AFs by MTT. Data are expressed as the mean \pm SD $(n=6)$. Stimulation by TGF- $\beta 1$ for $24 \mathrm{~h},{ }^{*} \mathrm{P}<0.01$ compared to the control. Twenty-four hours after transfection, followed by another $24-\mathrm{h}$ stimulation by TGF- $\beta 1,{ }^{*} \mathrm{P}<0.01$ compared to TGF- $\beta 1$ alone.

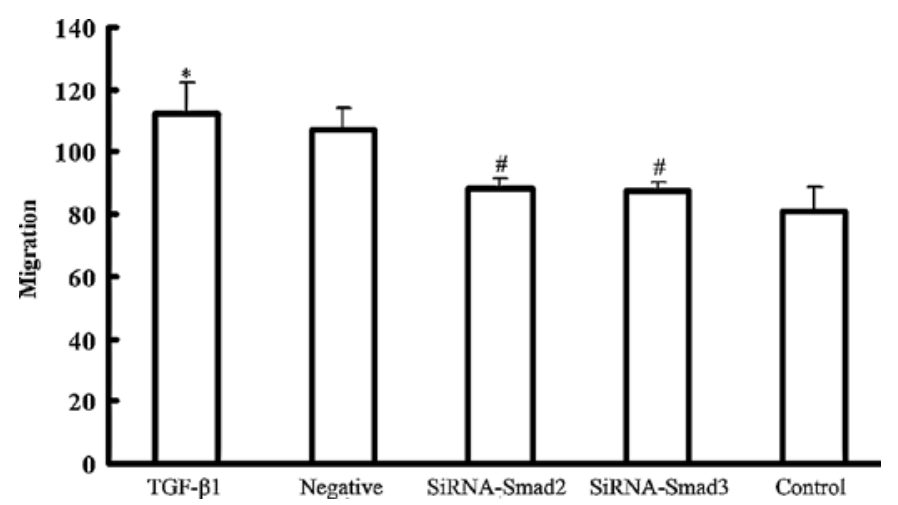

Figure 3. Effect of TGF- $\beta 1$ and siRNA on the migration of AFs measured by transwell chamber analysis. The number of migrated cells was counted in 5 random fields. Results are the mean \pm SD from at least three independent experiments. Stimulation by TGF- $\beta 1$ for $24 \mathrm{~h},{ }^{*} \mathrm{P}<0.01$ compared to the control. Twenty-four hours after transfection, followed by another 24-h stimulation by TGF- $\beta 1,{ }^{*} \mathrm{P}<0.01$ compared to TGF- $\beta 1$ alone.

The phosphorylation of Smad2 and Smad3 was enhanced upon challenge with TGF- $\beta 1$ for $24 \mathrm{~h}(\mathrm{P}<0.01)$ (Fig. 5B and C). When Smad2 and Smad3 expression was silenced with siRNA, the expression of pho-Smad2 and pho-Smad3 was attenuated $(\mathrm{P}<0.05)$ (Fig. 5B and C). Unfortunately, in the present study, the phosphorylation of Smad2 and Smad3 was not completely arrested by siRNA knockdown. This result may be associated with the time we selected to detect the protein levels or with the delayed degradation of Smad2 and 3.

We investigated the effect of Smad2 and 3 knockdown on TGF- $\beta 1$-induced SMA expression by RT-PCR and Western blotting. TGF- $\beta 1$-induced SMA expression was decreased by Smad 2 or 3 knockdown to an equal extent (Figs. $4 \mathrm{~B}$ and $5 \mathrm{~A}$ ). Thus, TGF- $\beta 1$-induced SMA expression depends on both the Smad 2 and 3 signaling pathways in AFs. An increase in collagen I and III expression was observed after $24 \mathrm{~h}$ of TGF- $\beta 1$ treatment (Figs. 4B and 5A), which suggests that collagen I and III are involved in the synthesis of ECM induced by TGF- $\beta 1$. This induction was inhibited by Smad 2 and 3 knockdown with siRNA, with no significant difference between their efficacy $(\mathrm{P}>0.05)$. Thus, the induction of collagen I and III by TGF- $\beta 1$ in AFs is both Smad2- and Smad3-dependent.
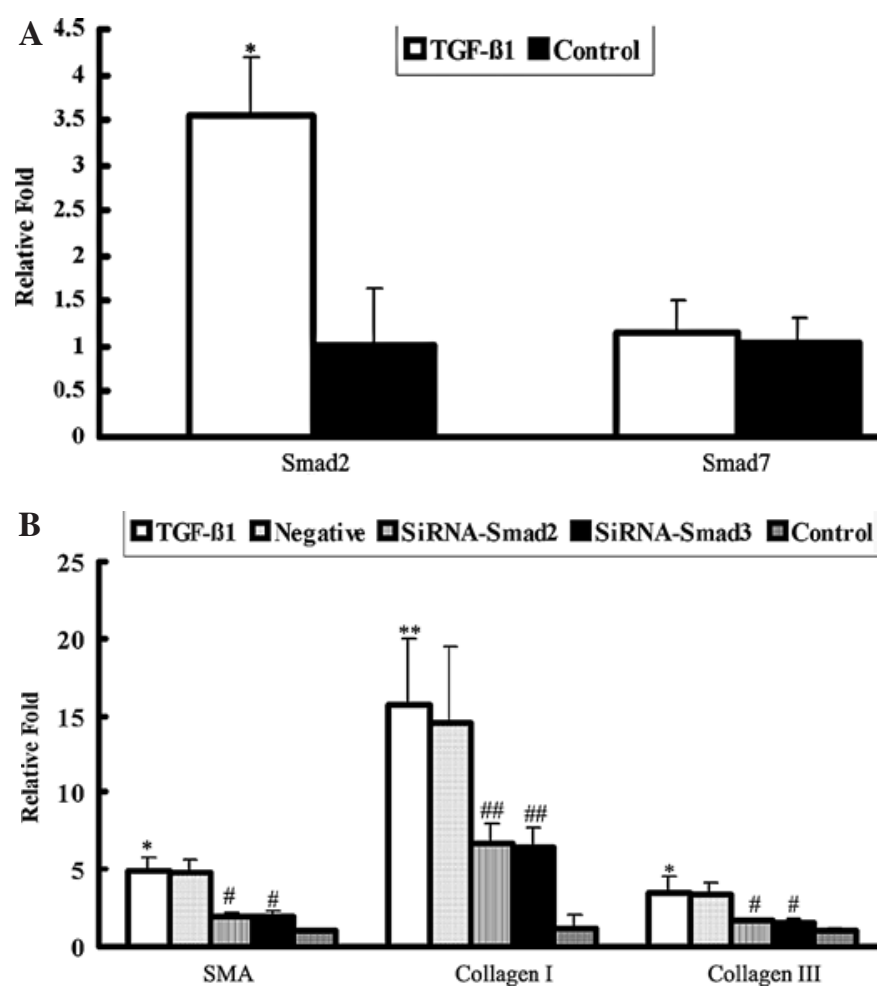

Figure 4. RT-PCR analysis of mRNA expression with TGF- $\beta 1$ and siRNA treatment. (A) mRNA expression of Smad2 and 7. Data are expressed as the mean $\pm \mathrm{SD}$. $\beta$-actin served as the internal standard. ${ }^{*} \mathrm{P}<0.01$ compared to the control. (B) Effect of siRNA on the mRNA expression of SMA and collagen I and III. Data are the mean \pm SD. $\beta$-actin served as the internal standard. ${ }^{*} \mathrm{P}<0.01 ;{ }^{* *} \mathrm{P}<0.05 ;{ }^{\#} \mathrm{P}<0.01 ;{ }^{\# \#} \mathrm{P}<0.05$ compared to the control or the TGF- $\beta 1$ group.

\section{Discussion}

Increasing evidence suggests that TGF- $\beta 1$ plays a key role in arterial remodeling processes. In the present study, we investigated the effect of TGF- $\beta 1$ on AFs in cell proliferation, migration, differentiation and the synthesis of ECM. Our results suggest that TGF- $\beta 1$ is a risk factor for vascular remodeling. Moreover, the roles of receptor-associated Smads (Smad2 and 3) were shown in the regulation of TGF- $\beta 1$-driven pro-fibrotic events in AFs. Our results demonstrate that Smad 2 and 3 are both required for inducing the proliferation and migration of AFs, and for increasing SMA and collagen I and III content in AFs, in response to TGF- $\beta 1$.

The origin of the cells that contribute to neointimal formation after endoluminal vascular injury has been widely debated. Currently, the adventitia is viewed as a key player during vascular growth and repair. Fibroblasts are the most abundant cell type of the adventitia. The migratory and proliferative responses of myofibroblasts, the specialized phenotype of activated fibroblasts, in addition to the synthesis of ECM, play essential roles during vascular remodeling. Nevertheless, the role of AFs in vascular remodeling remains disputed. The contribution of coronary AFs to neointimal formation was found to be negligible (17), but the research contained some limitations, such as the time, age of the animals and the recapitulation of the diseased vessels in humans after percutaneous transluminal coronary angioplasty. We found that the 
A TGF- $\beta 1$ Negative SiRNA-Smad2 SiRNA-Smad3 Control
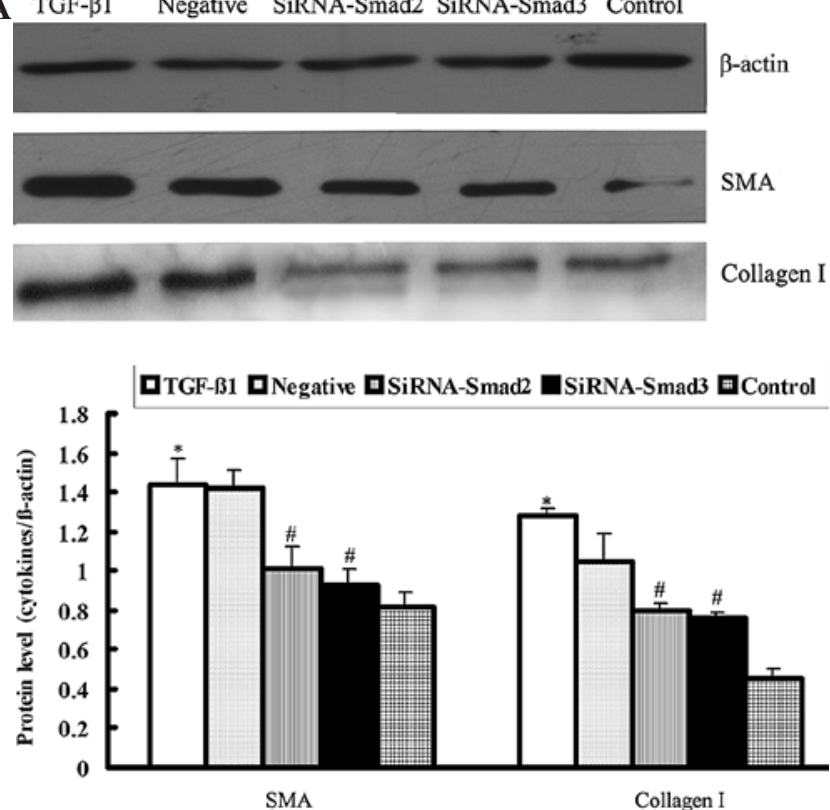

B
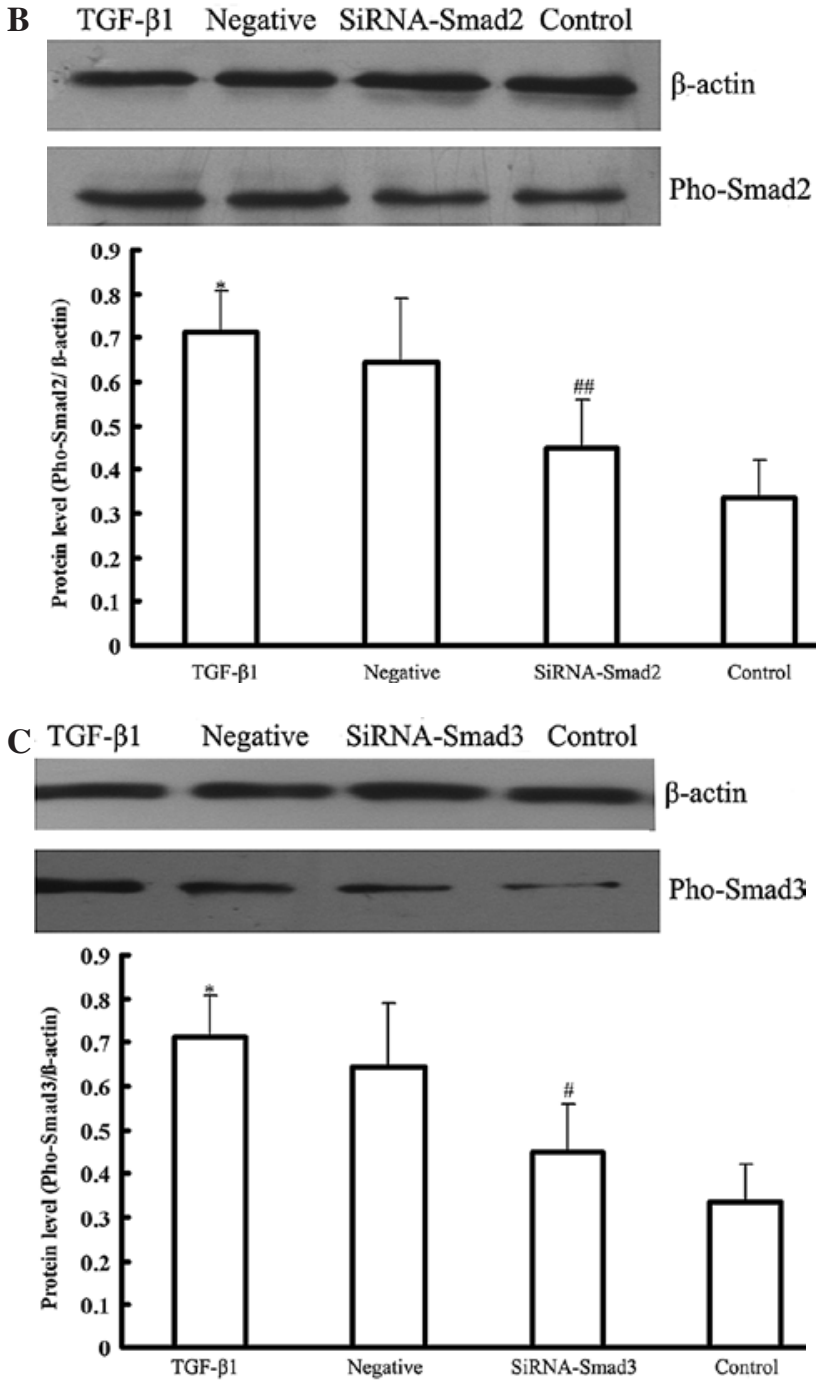

Figure 5. Western blot analysis of protein expression with TGF- $\beta 1$ and siRNA treatment. (A) Expression of SMA and Pro-COL1A1 protein. Results are the mean \pm SD. ${ }^{*}<<0.01$ compared to the control; ${ }^{*} \mathrm{P}<0.01$ compared to the TGF- $\beta 1$ group. (B) Expression of phosphorylated Smad2. Results are the mean $\pm \mathrm{SD}$. ${ }^{*} \mathrm{P}<0.01$ compared to the control; ${ }^{\# \#} \mathrm{P}<0.05$ compared to the TGF- $\beta 1$ group. (C) Expression of phosphorylated Smad3. Results are the mean \pm SD. ${ }^{*} \mathrm{P}<0.01$ compared to the control; ${ }^{*} \mathrm{P}<0.01$ compared to the TGF- $\beta 1$ group. proliferation, migration, differentiation and collagen composition of AFs increased under the influence of TGF- $\beta 1$.

TGF- $\beta 1$, the most potent mediator of myofibroblast differentiation, induces SMA expression in fibroblastic cells $(18,19)$ and affects the migration, proliferation and synthesis of collagens and other matrix components of fibroblasts $(20,21)$. Myofibroblasts originating from adventitia play a crucial role in neointimal formation and remodeling after coronary injury (22). TGF- $\beta 1$ signals through transmembrane receptor serine/ threonine kinases that activate the cytoplasmic proteins Smads to regulate cell proliferation, differentiation and death (23). Our results showed that TGF- $\beta 1$-induced SMA expression depended on both Smad2 and Smad3 in AFs. Moreover, Smad7 expression is induced by TGF- $\beta 1$ and may act via an autoregulatory negative feedback loop (24). We found no significant change in Smad7 gene expression after TGF- $\beta 1$ stimulation for $24 \mathrm{~h}$, which was consistent with previous reports $(15,16)$.

Cross-talk among Smad, mitogen-activated protein kinase (MAPK) and integrin signaling pathways may account for the mechanisms of AF function (12). SMC expression is regulated by p38 MAPK, extracellular-regulated signal kinase $1 / 2$ and Smad signaling in renal proximal tubular cells induced by TGF- $\beta 1$ (25). TGF- $\beta 1$ inducing fibroblast transdifferentiation to myofibroblasts is involved in integrin-mediated signaling and focal adhesion kinase (26). The Smad signaling pathway is the most classical pathway induced by TGF- $\beta 1$. The signaling molecules Smad 2 and 3 play a key role in the progression of renal fibrosis (27). Smad3 mediates TGF- $\beta 1$-induced collagen I expression in human mesangial cells (28). As well, Smad3 and pho-Smad3 contribute to liver fibrosis (29). Hu et al have shown that TGF- $\beta 1$ may contribute to the up-regulation of $\alpha$-SMA via Smad3 in rat lung fibroblasts (30). Any adventitial effect of Smad3 overexpression was found to be indirect, mediated by infected medial or neointimal cells (31), but this research did not have a relevant control group to exclude other factors that up-regulated Smad3 overexpression directly in adventitia. In our study, we found that after direct induction by TGF- $\beta 1$, Smad 3 and pho-Smad3 were increased. Although many profibrotic genes principally mediated by Smad3, Smad2 and the phosphorylation of Smad2 play critical roles in human tenon fibroblast stimulation by TGF- $\beta 1$ and scar formation $(32,33)$, our finding suggested that $\operatorname{Smad} 2$ and 3 both work as critical factors in AF proliferation and migration induced by TGF- $\beta 1$. Both Smad 2 and 3 knockdown attenuated proliferation, migration and TGF- $\beta 1$-based SMA gene activation in myofibroblasts. Rhubarb has been found to attenuate the TGF- $\beta 1$-mediated migration of hepatic stellate cells by interfering with Smad 2 and 3 phosphorylation (34).

Collagen types I and III, the major components of the ECM, play a role in the remodeling of the aortic wall in response to hypertension (35). Our study showed that the mRNA and protein levels of collagen I and III were down-regulated after intervention by siRNA-Smad 2 and siRNA-Smad3 with TGF- $\beta 1$ stimulation for $24 \mathrm{~h}$ as compared to TGF- $\beta 1$ alone, with no significant difference between Smad2 and Smad3 knockdown. Smad3 is usually considered the key mediator of fibrotic response, whereas Smad2 is more limited. Smad3 has been shown to play a role in the TGF- $\beta 1$-mediated induction of collagen expression (36). However, the knockdown 
of Smad2 also prevents the effect of TGF- $\beta 1$ in enhancing $\alpha 1$ (I) collagen promoter (37). There is evidence to suggest that tetrandrine suppresses Smad2 signaling and fibrogenic responses in association with Smad7 up-regulation in human subconjunctival fibroblasts (38). We conclude that the TGF- $\beta 1$ induced ECM synthesis of AFs may be involved in both the Smad2 and Smad 3 signaling pathways.

In conclusion, we found that TGF- $\beta 1$ initiated the proliferation, migration, differentiation and collagen synthesis of AFs, and that the mechanism is critically dependent on Smad2 and Smad3. Our study supports that both Smad2 and Smad3 are key mediators of TGF- $\beta 1$-induced AF activity.

\section{Acknowledgements}

This study was sponsored by the National Natural Science Foundation of China (no. 30873324).

\section{References}

1. Schulze-Bauer CA, Regitnig P and Holzapfel GA: Mechanics of the human femoral adventitia including the high-pressure response. Am J Physiol Heart Circ Physiol 282: 2427-2440, 2002.

2. Sartore S, Chiavegato A, Faggin E, Franch R, Puato M, Ausoni S and Pauletto P: Contribution of adventitial fibroblasts to neointima formation and vascular remodeling: from innocent bystander to active participant. Circ Res 89: 1111-1121, 2001.

3. McGrath JC, Deighan C, Briones AM, Shafaroudi MM, McBride M, Adler J, Arribas SM, Vila E and Daly CJ: New aspects of vascular remodelling: the involvement of all vascular cell types. Exp Physiol 90: 469-475, 2005.

4. Kantachuvesiri S, Fleming S, Peters J, Peters B, Brooker G, Lammie AG, McGrath I, Kotelevtsev Y and Mullins JJ: Controlled hypertension, a transgenic toggle switch reveals differential mechanisms underlying vascular disease. J Bio Chem 276: 36727-36733, 2001.

5. Kalluri R and Neilson EG: Epithelial-mesenchymal transition and its implications for fibrosis. J Clin Invest 112: 1776-1784, 2003.

6. Massague J and Wotton D: Transcriptional control by the TGF-beta/Smad signaling system. EMBO J 19: 1745-1754, 2000.

7. Leask A and Abraham DJ: The role of connective tissue growth factor, a multifunctional matricellular protein in fibroblast biology. Biochem Cell Biol 81: 355-363, 2003.

8. Siow RC and Churchman AT: Adventitial growth factor signalling and vascular remodelling: potential of perivascular gene transfer from the outside-in. Cardiovasc Res 75: 659-668, 2007.

9. Zhang F and Laiho M: On and off: proteasome and TGF-beta signaling. Exp Cell Res 291: 275-281, 2003.

10. Goldberg MT, Han YP, Yan C, Shaw MC and Garner WL: TNF-alpha suppresses alpha-smooth muscle actin expression in human dermal fibroblasts: an implication for abnormal wound healing. J Invest Dermatol 127: 2645-2655, 2007.

11. Jinnin $\mathrm{M}$, Ihn $\mathrm{H}$ and Tamaki K: Characterization of SIS3, a novel specific inhibitor of Smad3, and its effect on transforming growth factor-betal-induced extracellular matrix expression. Mol Pharmacol 69: 597-607, 2006.

12. Liu P, Zhang C, Feng JB, Zhao YX, Wang XP, Yang JM, Zhang MX, Wang XL and Zhang Y: Cross talk among Smad, MAPK, and integrin signaling pathways enhances adventitial fibroblast functions activated by transforming growth factorbetal and inhibited by Gax. Arterioscler Thromb Vasc Biol 28 725-731, 2008.

13. Reisdorf P, Lawrence DA, Sivan V, Klising E and Martin MT: Alteration of transforming growth factor- $\beta 1$ response involves down-regulation of Smad3 signaling in myofibroblasts from skin fibrosis. Am J Pathol 159: 263-272, 2001.

14. Ren M, Zhang J, Wang B, Liu P, Jiang H, Liu G and Yin H: Qindan-capsule inhibits proliferation of adventitial fibroblasts and collagen synthesis. J Ethnopharmacol 129: 53-58, 2010.
15. Mori Y, Chen SJ and Varga J: Modulation of endogenous Smad expression in normal skin fibroblasts by transforming growth factor-beta. Exp Cell Res 258: 374-383, 2000.

16. Wang B, Hao J, Jones SC, Yee MS, Roth JC and Dixon IM: Decreased Smad 7 expression contributes to cardiac fibrosis in the infarcted rat heart. Am J Physiol Heart Circ Physiol 282: 1685-1696, 2002.

17. Fleenor BS and Bowles DK: Negligible contribution of coronary adventitial fibroblasts to neointimal formation following balloon angioplasty in swine. Am J Physiol Heart Circ Physiol 296: 1532-1539, 2009.

18. Vaughan MB, Howard EW and Tomasek JJ: Transforming growth factor-betal promotes the morphological and functional differentiation of the myofibroblast. Exp Cell Res 257: 180-189, 2000.

19. Dugina V, Fontao L, Chaponnier C, Vasiliev J and Gabbiani G: Focal adhesion features during myofibroblastic differentiation are controlled by intracellular and extracellular factors. J Cell Sci 114: 3285-3296, 2001.

20. Ghosh AK, Yuan W, Mori Y, Chen S and Varga J: Antagonistic regulation of type I collagen gene expression by interferongamma and transforming growth factor-beta. Integration at the level of p300/CBP transcriptional coactivators. J Biol Chem 276: 11041-11048, 2001.

21. Petrov VV, Fagard RH and Lijnen PJ: Transforming growth factorbeta (1) induces angiotensin-converting enzyme synthesis in rat cardiac fibroblasts during their differentiation to myofibroblasts. J Renin Angiotensin Aldo Sterone Syst 1: 342-352, 2000.

22. Shi Y, Niculescu R, Wang D, Ormont M, Magno $M$, SanAntonio JD, Williams KJ and Zalewski A: Myofibroblast involvement in glycosaminoglycan synthesis and lipid retention during coronary repair. J Vasc Res 37: 399-407, 2000.

23. Moustakas A, Souchelnytskyi S and Heldin CH: Smad regulation in TGF- $\beta$ signal transduction. J Cell Sci 114: 4359-4369, 2001.

24. Landström M, Heldin NE, Bu S, Hermansson A, Itoh S, ten Dijke P and Heldin CH: Smad7 mediates apoptosis induced by transforming growth factor beta in prostatic carcinoma cells. Curr Biol 10: 535-538, 2000.

25. Sebe A, Leivonen SK, Fintha A, Masszi A, Rosivall L, Kähäri VM and Mucsi I: Transforming growth factor-beta-induced alphasmooth muscle cell actin expression in renal proximal tubular cells is regulated by p38beta mitogen-activated protein kinase, extracellular signal-regulated protein kinase1,2 and the Smad signalling during epithelial-myofibroblast transdifferentiation. Nephrol Dial Transplant 23: 1537-1545, 2008.

26. Ding Q, Gladson CL, Wu H, Hayasaka H and Olman MA: Focal adhesion kinase (FAK)-related non-kinase inhibits myofibroblast differentiation through differential MAPK activation in a FAK-dependent manner. J Biol Chem 283: 26839-26849, 2008.

27. Wang W, Koka V and Lan HY: Transforming growth factor-beta and Smad signalling in kidney diseases. Nephrology 10: 48-56, 2005.

28. Runyan CE, Schnaper HW and Poncelet AC: Smad3 and PKCס mediate TGF- $\beta 1$-induced collagen I expression in human mesangial cells. Am J Physiol Renal Physiol 285: 413-422, 2003.

29. Inagaki Y, Mamura M, Kanamaru Y, Greenwel P, Nemoto T, Takehara K, ten Dijke P and Nakao A: Constitutive phosphorylation and nuclear localization of Smad3 are correlated with increased collagen gene transcription in activated hepatic stellate cells. J Cell Physiol 187: 117-123, 2001.

30. Hu B, Wu Z and Phan SH: Smad3 mediates transforming growth factor- $\beta$-induced $\alpha$-smooth muscle actin expression. Am J Respir Cell Mol Biol 29: 397-404, 2003.

31. Kundi R, Hollenbeck ST, Yamanouchi D, Herman BC, Edlin R, Ryer EJ, Wang C, Tsai S, Liu B and Kent KC: Arterial gene transfer of the TGF-beta signalling protein Smad3 induces adaptive remodelling following angioplasty: a role for CTGF. Cardiovasc Res 84: 326-335, 2009.

32. Meyer-Ter-Vehn T, Gebhardt S, Sebald W, Buttmann M, Grehn F, Schlunck G and Knaus P: p38 inhibitors prevent TGF-betainduced myofibroblast transdifferentiation in human tenon fibroblasts. Invest Ophthalmol Vis Sci 47: 1500-1509, 2006.

33. Xiao YQ, Liu K, Shen JF, Xu GT and Ye W: SB-431542 inhibition of scar formation after filtration surgery and its potential mechanism. Invest Ophthalmol Vis Sci 50: 1698-1706, 2009. 
34. Lin YL, Wu CF and Huang YT: Effects of rhubarb on migration of rat hepatic stellate cells. J Gastroenterol Hepatol 24: 453-461, 2009.

35. Xu C, Zarins CK, Pannaraj PS, Bassiouny HS and Glagov S: Hypercholesterolemia superimposed by experimental hypertension induces differential distribution of collagen and elastin. Arterioscler Thromb Vasc Biol 20: 2566-2572, 2000.

36. Schnabl B, Kweon YO, Frederick JP, Wang XF, Rippe RA and Brenner DA: The role of Smad3 in mediating mouse hepatic stellate cell activation. Hepatology 34: 89-100, 2001.
37. Sysa P, Potter JJ, Liu X and Mezey E: Transforming growth factor-beta1 up-regulation of human alpha (1) (I) collagen is mediated by $\mathrm{Sp} 1$ and Smad2 transacting factors. DNA Cell Biol 28: 425-434, 2009.

38. Kitano A, Yamanaka O, Ikeda K, Ishida-Nishikawa I, Okada Y, Shirai K and Saika S: Tetrandrine suppresses activation of human subconjunctival fibroblasts in vitro. Curr Eye Res 33: 559-565, 2008. 